\title{
Effect of indacaterol on lung deflation improves cardiac performance in hyperinflated COPD patients: an interventional, randomized, double- blind clinical trial
}

\author{
This article was published in the following Dove Press journal: \\ International Journal of COPD \\ II September 2015 \\ Number of times this article has been viewed
}

\author{
Pierachille Santus ${ }^{1,2}$ \\ Dejan Radovanovic ${ }^{1,2}$ \\ Silvia Di Marco ${ }^{3}$ \\ Vincenzo Valenti ${ }^{4,5}$ \\ Rita Raccanelli ${ }^{1,2}$ \\ Francesco Blasi ${ }^{6,7}$ \\ Stefano Centanni ${ }^{8,9}$ \\ Maurizio Bussotti ${ }^{3}$ \\ 'Department of Health Sciences, \\ University of Milan, ${ }^{2}$ Pulmonary \\ Rehabilitation Unit, Fondazione \\ Salvatore Maugeri Scientific Institute \\ of Milan-IRCCS, ${ }^{3}$ Cardiological \\ Rehabilitation Unit, Fondazione \\ Salvatore Maugeri Rehabilitation \\ Institute of Milan-IRCCS, \\ ${ }^{4}$ Department of Biomedical Sciences \\ for Health, University of Milan, \\ ${ }^{5}$ Respiratory Unit, Policlinico San \\ Donato-IRCCS, San Donato Milanese, \\ ${ }^{6}$ Department of Pathophysiology \\ and Transplantation, University of \\ Milan, ${ }^{7}$ IRCCS Fondazione Ospedale \\ Maggiore Policlinico Cà Granda Milan, \\ ${ }^{8}$ Department of Health Sciences, \\ University of Milan, ${ }^{9}$ Respiratory Unit, \\ Ospedale San Paolo, Milan, Italy
}

Correspondence: Pierachille Santus Department of Health Sciences, University of Milan, Pulmonary Rehabilitation Unit, Fondazione Salvatore Maugeri, Istituto Scientifico di Milano IRCCS, Via Camaldoli, 64 - 20138 Milan, Italy

Tel +390250725I22

Fax +390250725240

Email pierachille.santus@unimi.it
Background: COPD is often associated with cardiovascular comorbidity. Treatment guidelines recommend therapy with bronchodilators as first choice. We investigated the acute effect of single-dose indacaterol on lung hyperinflation in COPD subjects, for the first time evaluating the potential effects on right heart performance.

Methods: In this Phase IV, randomized, interventional, double-blind, crossover clinical study, we recruited 40 patients (50-85 years of age) with stable COPD. Patients were treated with $150 \mu \mathrm{g}$ indacaterol or placebo and after 60 minutes (T60) and 180 minutes (T180) the following tests were performed: trans-thoracic echocardiography (TTE), plethysmography, diffusing capacity of the lung for carbon monoxide, saturation of peripheral oxygen, and visual analog scale dyspnea score. Patients underwent a crossover re-challenge after a further 72 hours of pharmacological washout. All TTE measurements were conducted blindly by the same operator and further interpreted by two different blinded operators. Consensus decisions were taken on every value and parameter. The primary outcome was the effect of the reduction of residual volume and functional residual capacity on right heart systolic and diastolic function indexes evaluated by TTE in patients treated with indacaterol, as compared to placebo.

Results: Vital capacity, inspiratory capacity, and forced expiratory volume in 1 second were significantly increased by indacaterol, when compared with placebo, while residual volume, intrathoracic gas volume, and specific airway resistance were significantly reduced in patients treated with indacaterol. Tricuspid annular plane systolic excursion was significantly increased versus placebo, paralleled by an increase of tricuspid E-wave deceleration time. The cardiac frequency was also significantly reduced in indacaterol-treated patients.

Conclusion: Indacaterol significantly reduces lung hyperinflation in acute conditions, with a clinically relevant improvement of dyspnea. These modifications are associated with a significant increase of the right ventricular compliance indexes and may have a role in improving left ventricular preload leading to a reduction in cardiac frequency.

Keywords: lung deflation, bronchodilator, cardiac performance, right ventricular function, echocardiography

\section{Introduction}

COPD is characterized by persistent airflow limitation, pulmonary hyperinflation, and impaired ventilation homogeneity. COPD is often associated with various comorbidities, mainly cardiovascular and metabolic in nature, and ranks third among the causes of death worldwide. ${ }^{1}$ 
A form of COPD is chronic obstructive bronchitis, causing narrowed airways, persistent cough, and excess mucus production. Severe COPD partially overlaps with emphysema, accompanied by destruction of alveolar walls and permanent enlargement of lung regions. The loss of lung parenchyma and the supporting elastic structures leads to the loss of pulmonary elastic recoil. This causes increased resistance, airflow obstruction, air trapping, and lung hyperinflation. This frequently results in dyspnea which is responsible for the limitation of daily activities in COPD patients. ${ }^{2,3}$

The correlation between emphysema and altered left ventricular (LV) end-diastolic volume is well established., ${ }^{4,5}$ Notwithstanding, little is known about the effects of these alterations on heart mechanical functions. The large MultiEthnic Study of Atherosclerosis (MESA) study, combining measurements of right ventricular (RV) structure and function with assessment of emphysema, showed that percent emphysema was inversely correlated to RV end-diastolic volumes, stroke volume, and mass, likely associated with increased lung vascular resistance and pulmonary hyperinflation. ${ }^{6}$ A frequent complication of very severe COPD is cor pulmonale, a structural alteration with function impairment of the right ventricle, leading to increased pulmonary vascular resistance and right heart failure. This condition is accompanied by the reductions in LV filling, LV stroke volume, and cardiac output, while left ventricular ejection fraction (LVEF) is usually maintained. ${ }^{4}$ A study conducted on a large cohort of patients with heart failure, either with preserved or with reduced LVEF, evaluated prevalence and prognostic impact of the noncardiac comorbidities in the two groups. The result of this survey revealed that COPD was the sole comorbidity significantly associated with an higher hazard for mortality in patients with preserved EF, although COPD was an independent predictor of mortality in both the groups. ${ }^{7}$ These studies highlight the importance of investigating the relationships between heart and lung structure and function.

COPD has been treated with bronchodilators and corticosteroids and for the last two decades long-acting $\beta 2$-agonists (LABAs) have been the mainstay of the management of COPD, according to the guidelines of the Global Initiative for Chronic Obstructive Lung Disease (GOLD). ${ }^{3}$ These agents relax airway smooth muscle and augment expiratory airflow, with reduced hyperinflation and improvement of dyspnea, functional capacity, and patient quality of life. More recently, ultraLABAs, like the novel once-daily LABA indacaterol, ${ }^{8}$ have been also approved for COPD. They have an ultra-long duration of action (at least 24 hours) and rapid bronchodilation activity (within 5 minutes). ${ }^{9}$ Several clinical studies revealed that indacaterol has comparable or even superior clinical efficacy than the previously available LABAs. ${ }^{10-17}$

Aim of the study reported here was to evaluate the acute effect of a single-dose of the long-acting $\beta 2$ agonist indacaterol $150 \mu \mathrm{g}$ on lung hyperinflation in COPD subjects with lung air trapping, and the consequent potential effects on right heart systolic and diastolic functional indexes.

\section{Materials and methods Study design and patients}

This was a Phase IV, monocentric, randomized, prospective, interventional, double-blind, placebo-controlled, crossover study. The protocol was approved by the Central Ethic Committee (CEC) of the Salvatore Maugeri Foundation. All patients provided their written informed consent.

The main inclusion criteria were patients aged $50-85$ years, former or active smokers with a history of COPD of at least 1 year and defined according to GOLD 2013 criteria, ${ }^{3}$ clinically stable in the last 3 months, with forced respiratory volume in 1 second $\left(\mathrm{FEV}_{1}\right)$ pred $\leq 70 \%$ and a residual volume ( $R V_{0}$ ) pred $\geq 135 \%$, and absence of cardiac comorbidities.

\section{Procedures}

Between November 2013 and October 2014, we recruited and enrolled a total of 40 eligible patients with COPD. Patients were randomly allocated in a 1:1 ratio to receive either $150 \mu \mathrm{g}$ indacaterol or placebo. Following the washout of the inhalation therapy (T0), patients were treated with $150 \mu \mathrm{g}$ indacaterol or placebo. After 60 minutes (T60) and 180 minutes (T180) the following tests were performed: trans-thoracic echocardiography (TTE), plethysmography, diffusing capacity of the lung for carbon monoxide, saturation of peripheral oxygen, and visual analog scale (VAS) dyspnea score. The VAS dyspnea score ranged from 0 (no dyspnea at rest) to 10 (unbearable dyspnea) and it was recorded by the same blinded operator. Patients underwent a crossover re-challenge after a further 72 hours of pharmacological washout (Figure 1).

All echocardiography examinations were performed with a GE Vivid 7 Dimension ultrasound system (GE HealthCare UK Ltd, Little Chalfont, UK). A complete standard M-mode and two-dimensional echocardiography examinations were performed according to our clinical laboratory practice using a S5-1 sector array probe. All measurements were made on three representative beats and the results were averaged. The following parameters were evaluated to study right heart size and systolic and diastolic function: RV size, right atrial size, RVEF, tricuspid annular plane systolic excursion (TAPSE), 


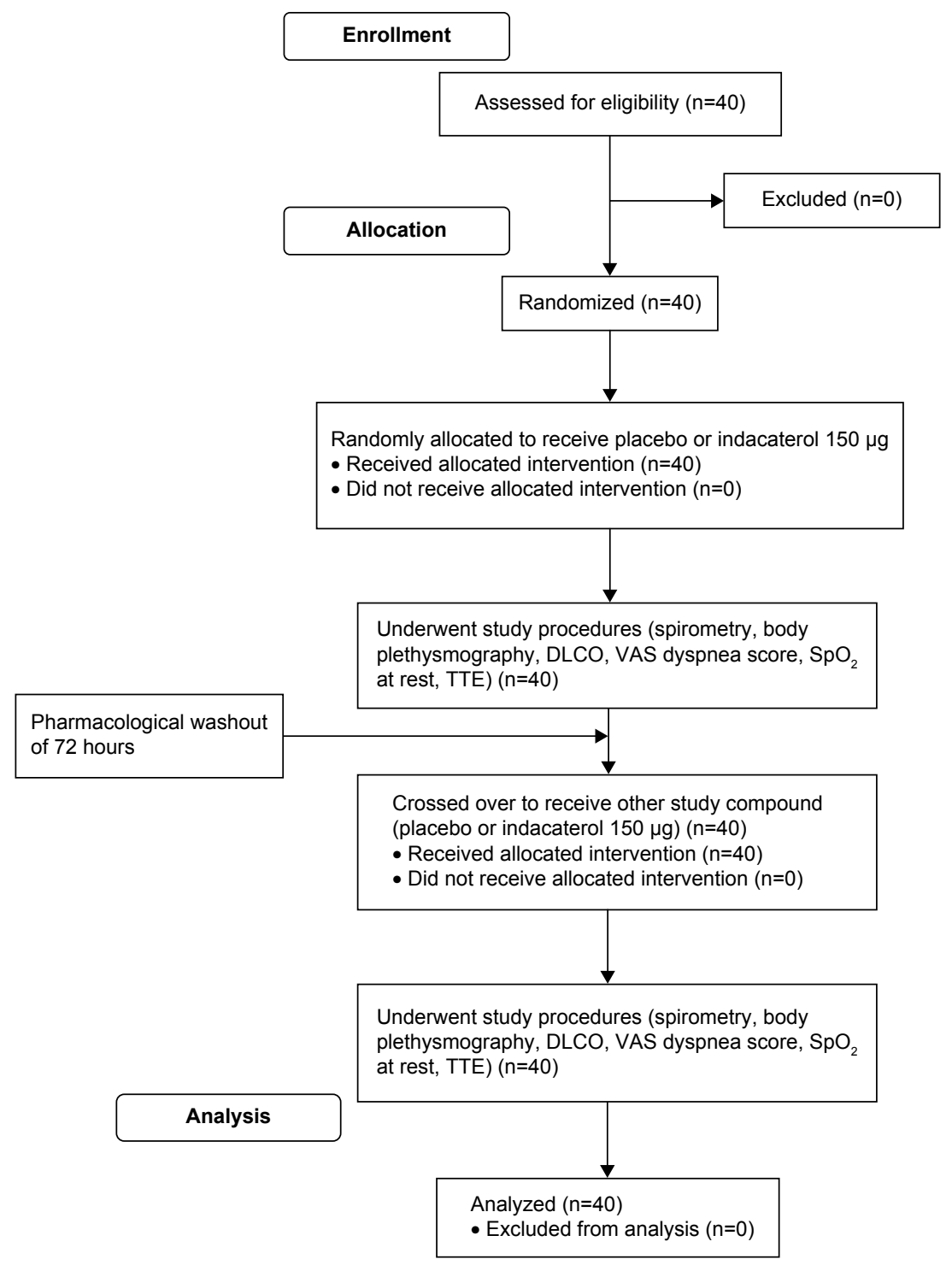

Figure I Consolidated Standards of Reporting Trials (CONSORT) 2010 flow diagram.

Notes: The diagram graphically outlines the design and conduct of the clinical study.

Abbreviations: DLCO, diffusing lung capacity for carbon monoxide; $\mathrm{SpO}_{2}$, peripheral oxygen saturation; TTE, trans-thoracic echocardiography; VAS, visual analog scale.

systolic pulmonary artery pressure (sPAP) with an estimate of right atrial pressure on the basis of inferior vena cava size and collapse, tricuspid E/A ratio, tricuspid E/e' ratio, and tricuspid E-wave deceleration time (DT-TR). Left heart size and systolic and diastolic function were evaluated as follows: LV size, left atrial (LA) size, LVEF, mitral valve peak $\mathrm{E}$ and peak $\mathrm{A}, \mathrm{E} / \mathrm{A}$ mitral ratio, E/e' mitral ratio, mitral E-wave deceleration time (DT-MR).

TAPSE was expressed in millimeters $(\mathrm{mm})$, while measurements of DT-TR and DT-MR were expressed in milliseconds (msec).

Heart rate (HR) was recorded during all echocardiographic maneuvers.

\section{Outcomes}

The primary outcome was to evaluate the reduction of RVo and functional residual capacity induced by indacaterol and its effect on the following right cardiac systolic and diastolic functional indexes: RVEF, TAPSE, sPAP, tricuspid E/e' ratio, and DT-TR.

Additional outcomes after indacaterol treatment were the evaluation of: 1) interventricular septum motility modification; 2) modifications in cardiac LVEF, E/e' mitral ratio, DT-MR; and 3) right cardiac chambers kinetics modifications by TTE. Inspiratory capacity modifications and specific airway resistance (sRAW) were assessed by body plethysmography and spirometry. 
Table I Demographic, anthropometric, and baseline lung function variables

\begin{tabular}{lll}
\hline Variable & $\begin{array}{l}\text { Actual } \\
\text { value }\end{array}$ & $\begin{array}{l}\text { Percent of predicted } \\
\text { values }\end{array}$ \\
\hline Study participants, $\mathrm{n}$ & 40 & \\
Age, years & $71.6 \pm 7.10$ & \\
Sex, M/F & $27 / 13$ & \\
Height, $\mathrm{m}$ & $1.64 \pm 0.10$ & \\
Weight, kg & $65.80 \pm 15.9$ & \\
BMI & $24.60 \pm 5.10$ & \\
Smoking history, pack-years & $41.20 \pm 10.60$ & \\
GOLD stage I-II, $\mathrm{n}$ & $0-10$ & \\
GOLD stage III-IV, n & $13-17$ & \\
FEV, L & $0.96 \pm 0.43$ & $41.40 \pm 17.20$ \\
VC, L & $2.71 \pm 0.85$ & $86.70 \pm 15.70$ \\
RVo, L & $4.70 \pm 1.34$ & $201.40 \pm 59.20$ \\
Room air SpO & $92.60 \pm 2.30$ & \\
HR, bpm & $71.60 \pm 10.50$ & \\
VAS dyspnea score & $1.40 \pm 1.90$ & \\
\hline NG: &
\end{tabular}

Note: Data are shown as mean \pm standard deviation.

Abbreviations: BMI, body mass index; $\mathrm{FEV}_{1}$, forced expiratory volume in I second; GOLD, Global Initiative for Chronic Obstructive Lung Disease; HR, heart rate; RVo, residual volume; $\mathrm{SpO}_{2}$, peripheral capillary oxygen saturation; VAS, visual analog scale; VC, vital capacity; bpm, beats per minute.

\section{Statistical analysis}

Statistical analyses were performed using SSPS (v 20.0; IBM Corporation, Armonk, NY, USA). Results were analyzed using the $t$-test for unpaired data with $\alpha=0.05$. All results were also compared using the $t$-test for paired data after analysis of covariance and Bonferroni correction was applied. Any difference with $P \leq 0.05$ was considered significant. All values are presented as mean \pm standard deviation, unless otherwise stated. The reported work was a pilot study; therefore, sample size was not calculated by power analysis, because of the absence of any data in the literature that could be reviewed. The trial is registered with ClinicalTrials.gov, number NCT01996124.

\section{Results}

This study has been conducted on a total of 40 COPD patients, from November 2013 to October 2014. Patients' demographics and baseline variables of lung functionality are reported in Table 1.

The dynamic respiratory parameters, vital capacity (VC), inspiratory capacity (IC), and $\mathrm{FEV}_{1}$ were recorded in all subjects under study by spirometric measurements at baseline (T0) and after 60 minutes (T60) and 180 minutes (T180) of indacaterol $150 \mu \mathrm{g}$ inhalation. Values are expressed as volumes (L) and as percent predicted (\% pred) as well. For all three parameters examined indacaterol $150 \mu \mathrm{g}$ treatment induced a significant increase, both at T60 and T180, as compared with T0. Particularly relevant increases of volumes were observed at $\mathrm{T} 180$ for $\mathrm{VC}$, IC, and $\mathrm{FEV}_{1}$. The differences were statistically significant also when calculated versus the treatment with placebo (Table 2). No significant modifications were found in the diffusing capacity of the lung for carbon monoxide and its subcomponents (alveolar volume and transfer coefficient) both after indacaterol and placebo treatment (data not shown).

As regards the static respiratory parameters, total lung capacity, RVo, intrathoracic gas volume (ITGV, a plethysmographic equivalent to functional residual capacity), and sRAW were evaluated by plethysmography. As in the case of dynamic volumes, the treatment with indacaterol $150 \mu \mathrm{g}$ provided the patients with a significant benefit, both at T60 and at T180. All parameters considered, total lung capacity, RVo, ITGV, and sRAW were significantly reduced, both when compared to $\mathrm{T} 0$ and placebo treatment (Table 3).

Following the evaluation of respiratory function parameters, TTE was performed.

With regard to right cardiac chambers, no changes in RVEF, sPAP mitral valve peak E and peak A, E/A mitral ratio, and E/e' mitral ratio were found.

After indacaterol, at T180 a significant increase of TAPSE was observed compared to T0, while at T60 the increase was significant when compared to the patients treated with placebo. In parallel, after indacaterol the DT-TR was significantly increased at T60 and T180 both

Table 2 Dynamic respiratory parameters after 60 and 180 minutes' treatment with indacaterol or placebo

\begin{tabular}{|c|c|c|c|c|c|c|}
\hline \multirow[t]{2}{*}{ Parameter } & \multicolumn{3}{|l|}{ Indacaterol } & \multicolumn{3}{|l|}{ Placebo } \\
\hline & T0 & $\Delta \mathrm{T} 60$ & $\Delta \mathrm{T} 180$ & T0 & $\Delta \mathrm{T} 60$ & $\Delta \mathrm{T} I 80$ \\
\hline IC, L & $1.94 \pm 0.64$ & $+0.14 \pm 0.35^{\#, *}$ & $+0.12 \pm 0.3 I^{\#, *}$ & $1.91 \pm 0.63$ & $+0.03 \pm 0.24$ & $+0.02 \pm 0.22$ \\
\hline IC, \% pred & $84.94 \pm 21.50$ & $+9.5 \mathrm{I} \pm 22.9 \mathrm{I}^{\# * *}$ & $+7.85 \pm 17.54^{\#, *}$ & $83.7 \pm 21.70$ & $+1.02 \pm 6.30$ & $+0.90 \pm 5.90$ \\
\hline VC, L & $2.7 I \pm 0.85$ & $+0.16 \pm 0.25^{\#, *}$ & $+0.22 \pm 0.27^{\#, *}$ & $2.70 \pm 0.87$ & $+0.01 \pm 0.14$ & $-0.04 \pm 0.21$ \\
\hline VC, \% pred & $86.68 \pm 15.69$ & $+6.85 \pm 9.75^{\#, *}$ & $+9.00 \pm 10.58^{\#, *}$ & $87.05 \pm 15.23$ & $+0.80 \pm 3.80$ & $-0.50 \pm 4.20$ \\
\hline $\mathrm{FEV}_{1}, \mathrm{~L}$ & $0.96 \pm 0.43$ & $+0.07 \pm 0.12^{\#, *}$ & $+0.08 \pm 0.13^{\#, *}$ & $0.94 \pm 0.46$ & $-0.01 \pm 0.16$ & $+0.01 \pm 0.15$ \\
\hline $\mathrm{FEV}_{1}$, \% pred & $41.45 \pm 17.16$ & $+7.75 \pm 10.9^{\#, *}$ & $+7.66 \pm 11.53^{\#, *}$ & $40.65 \pm 17.16$ & $+0.80 \pm 3.10$ & $+0.20 \pm 4.50$ \\
\hline VAS dyspnea & $1.40 \pm 1.90$ & $-0.48 \pm \mathrm{I} .0 \mathrm{I}^{\#, *}$ & $-0.80 \pm 1.30^{\#, *}$ & $1.30 \pm 1.92$ & $-0.20 \pm 0.55$ & $-0.25 \pm 1.15$ \\
\hline
\end{tabular}

Notes: Data are shown as mean \pm standard deviation. ${ }^{*} P \leq 0.05$ vs $T 0$ (baseline); ${ }^{*} \mathrm{P} \leq 0.05$ vs placebo. $\Delta=$ post-(T60 and $\left.\mathrm{T} \mid 80\right)(60$ and 180 minutes) minus pretreatment (T0) values.

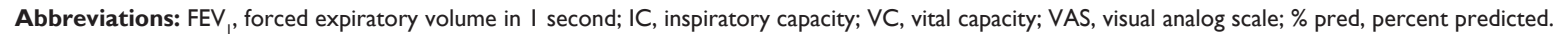


Table 3 Static respiratory parameters after 60 and 180 minutes' treatment with indacaterol or placebo

\begin{tabular}{|c|c|c|c|c|c|c|}
\hline \multirow[t]{2}{*}{ Parameter } & \multicolumn{3}{|l|}{ Indacaterol } & \multicolumn{3}{|l|}{ Placebo } \\
\hline & TO & $\Delta \mathrm{T} 60$ & $\Delta T 180$ & T0 & $\Delta \mathrm{T} 60$ & $\Delta \mathrm{T} 180$ \\
\hline TLC, L & $7.36 \pm 1.41$ & $-0.32 \pm 0.75^{*}$ & $-0.27 \pm 0.92 *$ & $7.33 \pm 1.39$ & $-0.04 \pm 0.82$ & $+0.03 \pm 0.85$ \\
\hline TLC, \% pred & $130.61 \pm 22.65$ & $-1.10 \pm 4.37^{*}$ & $-2.58 \pm 11.52 *$ & $129.50 \pm 21.87$ & $+0.20 \pm 5.20$ & $+0.90 \pm 9.87$ \\
\hline RVo, L & $4.70 \pm 1.34$ & $-0.48 \pm 0.85^{\#, *}$ & $-0.56 \pm 1.03^{\#, *}$ & $4.74 \pm|.3|$ & $-0.02 \pm 0.90$ & $+0.04 \pm 0.98$ \\
\hline RVo, \% pred & $201.42 \pm 59.25$ & $-8.61 \pm 13.44^{\#, *}$ & $-9.14 \pm 16.62^{\#, *}$ & $205.28 \pm 60.08$ & $-1.20 \pm 14.52$ & $+1.14 \pm 15.9$ \\
\hline ITGV, L & $5.50 \pm 1.42$ & $-0.43 \pm 6.55^{\#, *}$ & $-0.54 \pm\left. 0.9\right|^{\#, *}$ & $5.53 \pm I .4 \mid$ & $-0.06 \pm 7.82$ & $+0.01 \pm 0.95$ \\
\hline ITGV, \% pred & $|74.92 \pm 45.0|$ & $-6.55 \pm 10.97^{\#, *}$ & $-7.8 I \pm 12.36^{\#, *}$ & $176.47 \pm 44.87$ & $+1.2 \pm 11.12$ & $-0.01 \pm 11.49$ \\
\hline sRAW, $\mathrm{kPa} / \mathrm{s}$ & $4.31 \pm 2.39$ & $-0.75 \pm 0.87^{\#, *}$ & $-0.68 \pm 0.85^{\#, *}$ & $4.26 \pm 2.28$ & $-0.07 \pm 0.90$ & $+0.02 \pm 0.80$ \\
\hline sRAW, \% pred & $393.22 \pm 219.26$ & $-14.40 \pm 21.29^{\#, *}$ & $-13.11 \pm 18.02^{\#, *}$ & $390.14 \pm 221.20$ & $-0.80 \pm 16.42$ & $+0.60 \pm 18.26$ \\
\hline
\end{tabular}

Notes: Data are shown as mean \pm standard deviation. ${ }^{*} P \leq 0.05$ vs $T 0$ (baseline); ${ }^{*} P \leq 0.05$ vs placebo. $\Delta=$ post-(T60 and TI80) $(60$ and 180 minutes) minus pretreatment (T0) values.

Abbreviations: ITGV, intrathoracic gas volume; kPa/s, kilopascal per second; RVo, residual volume; sRAW, specific airway resistance; TLC, total lung capacity; \% pred, percent predicted.

versus $\mathrm{T} 0$ and placebo. HR was significantly reduced after treatment with indacaterol at all time points, while no significant variations were observed after treatment with placebo (Table 4).

No changes in LV function parameters were detected. In particular, LVEF together with mitral valve function parameters were not significantly modified both after indacaterol and placebo treatment.

Dyspnea evaluated with VAS score was significantly reduced after indacaterol at every time point as compared both to baseline and placebo (Table 2).

\section{Discussion}

This Phase IV, randomized, interventional study focused on the potential positive effect of indacaterol on the cardiac functions of COPD patients, based on two previous relevant advances in the field. On one hand, recent data reported the acute effects of indacaterol in reducing lung hyperinflation (inducing lung deflation) and alleviating dyspnea perception at rest in COPD patients. ${ }^{19}$ On the other hand, it has been shown that severe COPD with emphysema with the associated hyperinflation plays a key role on heart size reduction and cardiac dysfunction. ${ }^{4,5}$
Moreover, COPD was shown to be the sole comorbidity significantly associated with an increased risk of mortality in patients with heart failure, irrespective of the condition of the EF. ${ }^{7}$ This evidence further underscores the importance of preserving lung structure and function to improve heart conditions. Therefore, we hypothesized that the treatment of hyperinflated COPD patients with indacaterol, with its acute effect on lung deflation, may positively influence the cardiac parameters and the functionality of the right heart in particular. Given that the main effect of lung deflation induced by indacaterol is a decrease of RVo with consequent increase of IC, a RVo pred $\geq 135 \%$ was the most important criterion among the inclusion criteria of this study.

The inter-operator variability of echocardiography evaluations was overruled by the fact that all echocardiography measurements were conducted blindly by the same operator on all the patients under study and interpreted by two different blinded operators who discussed all the data and consequently consensus decision was taken in account. ${ }^{18}$ This procedure has been previously demonstrated to bring interobserver variability close to zero. ${ }^{19}$ The aim of the cardiac performance study was mechanical, not electric, functionality (no electrocardiograms were performed).

Table 4 Cardiac performance after 60 and 180 minutes' treatment with indacaterol or placebo

\begin{tabular}{|c|c|c|c|c|c|c|}
\hline \multirow[t]{2}{*}{ Parameter } & \multicolumn{3}{|l|}{ Indacaterol } & \multicolumn{3}{|l|}{ Placebo } \\
\hline & TO & $\Delta \mathrm{T} 60$ & $\Delta \mathbf{T} 180$ & TO & $\Delta \mathrm{T} 60$ & $\Delta \mathrm{T} 180$ \\
\hline TAPSE, mm & $22.30 \pm 3.52$ & $+0.05 \pm 1.28 *$ & $+0.4 \mathrm{I} \pm 1.07^{\#, *}$ & $21.90 \pm 3.83$ & $-0.03 \pm 1.26$ & $+0.02 \pm 3.80$ \\
\hline PAPs, mmHg & $33.03 \pm 8.10$ & $+0.7 I \pm 5.50$ & $-0.08 \pm 7.76$ & $32.78 \pm 8.30$ & $+0.77 \pm 4.46$ & $+0.24 \pm 5.76$ \\
\hline DT-TR, msec & $207.80 \pm 64.90$ & $+9.93 \pm 36.31 *$ & $+11.90 \pm 32.86^{\#, *}$ & $206.70 \pm 65.84$ & $+2.60 \pm 35.90$ & $+3.80 \pm 38.90$ \\
\hline LVEF, \% & $61.80 \pm 5.25$ & $-0.03 \pm 1.90$ & $-0.25 \pm 2.20$ & $60.60 \pm 6.21$ & $+0.09 \pm 2.12$ & $-0.14 \pm 2.35$ \\
\hline DT-MR, msec & $230.18 \pm 58.69$ & $+3.98 \pm 38.24$ & $+4.33 \pm 38.79$ & $228.25 \pm 59.33$ & $+1.12 \pm 37.52$ & $+|.38 \pm 36.8|$ \\
\hline HR, bpm & $71.54 \pm 10.60$ & $-1.95 \pm 5.30^{\#, *}$ & $-2.00 \pm 6.10^{\#, *}$ & $70.21 \pm 9.40$ & $-0.80 \pm 1.20$ & $+0.60 \pm 1.30$ \\
\hline
\end{tabular}

Notes: Data are shown as mean \pm standard deviation. ${ }^{*} \mathrm{P} \leq 0.05$ vs $\mathrm{T0}$ (baseline); $* \mathrm{P} \leq 0.05$ vs placebo. $\Delta=$ post-(T60 and TI80) $(60$ and 180 minutes) minus pretreatment (T0) values.

Abbreviations: bpm, beats per minute; DT-TR, tricuspid E-wave deceleration time; HR, heart rate; LVEF, left ventricular ejection fraction; DT-MR, mitral E-wave deceleration time; msec, milliseconds; PAPs, systolic pulmonary artery pressure; TAPSE, tricuspid annular plane systolic excursion. 
In agreement with previously reported outcomes, ${ }^{20,21}$ the results of this study reveal that indacaterol significantly reduces lung hyperinflation versus placebo in acute conditions, and leads to a clinically relevant improvement in dyspnea perception at rest in COPD patients. These positive effects are accompanied by a significant increase in RV compliance. After 180 minutes following indacaterol inhalation, TAPSE and DT-TR show a significant improvement.

Moreover, a statistically significant reduction of cardiac frequency was observed. This is particularly relevant because it was accompanied by a concomitant reduction in dyspnea, which parallels lung deflation. The mechanical effort of accessory respiratory muscles during patient respiration was consequently reduced, as was the needed heart output. The reduction of transparietal pressure appears to play an important role in improving diastolic right cardiac indexes ${ }^{22}$ and together with the reduced work of breathing may be responsible for the reduction in HR. In one of the first studies to make a complete echocardiographic assessment of COPD patients, Boussuges et a ${ }^{23}$ described a reduced LV preload in COPD patients that could be secondary to many factors, such as increased $\mathrm{HR}$, increased positive end expiratory pressure (PEEP), chronic hypoxia ${ }^{24}$ and relative hypovolemia. The reduced right venous return secondary to PEEP increase can be therefore responsible for an impaired LV filling and increased cardiac frequency. All the patients in our study had chronic hypoxemia, that may be, per se, indirectly responsible for impaired LV preload (mean saturation of peripheral oxygen $92.6 \%$, Table 1). In our study, by reducing hyperinflation, and therefore PEEP, we favor the right venous return, thus possibly influencing the diastolic filling pattern of the left ventricle and allowing a reduction in HR.

Unfortunately, we were not able to measure any changes in diastolic and systolic LV indexes. This might be due to two major issues: the first one may rely on the higher working pressures of the $\mathrm{LV}$, therefore being affected to a lesser extent by the variations of intrathoracic pressure than the RV, thus leading to smaller measurable changes. Secondly, taking in to account the observation made earlier and the previous literature on the topic, echocardiography may not represent the most sensible tool in detecting the tiny changes that occur in the left heart chambers, especially in hyperinflated patients with air trapping. Indacaterol has a well-known good safety profile, ${ }^{11}$ although potentially leads to tachycardia ${ }^{25,26}$ that, however, was not recorded for any patients of the present study.

Our study focused on acute effects only and this may be viewed as a limitation. However, as far as we are aware, this is the first study on the effect of indacaterol on the heart function of COPD patients, and, given the positive acute effects observed, it can be the starting point for further longterm studies on the effect of pulmonary deflation on heart functionality.

\section{Acknowledgments}

The authors thank Dr Paola Corbo for her technical collaboration in performing the echocardiographic evaluations. Editorial assistance was provided by Health Publishing and Services, Milan, Italy, and unconditionally supported by Novartis Farma, Italy.

\section{Author contributions}

All authors contributed toward data analysis, design, drafting and revising the paper and agree to be accountable for all aspects of the work. All authors had access to all the data and guarantee for the accuracy of the reported data.

\section{Disclosure}

PS has received financial support for research from Pfizer, Almirall, Chiesi Farmaceutici, and AirLiquide. He has received honoraria for lectures at national meetings from Chiesi Farmaceutici, Novartis, Zambon Italia, AstraZeneca, Almirall, GlaxoSmithKline, Boehringer Ingelheim, Menarini, and Malesci-Guidotti. He has served as consultant for Zambon Italia, AstraZeneca, Novartis, Chiesi Farmaceutici, and Boehringer Ingelheim. PS states that no funding sources influenced the preparation of the current manuscript or were involved in the collection, interpretation, and presentation of data.

FB has received financial support for research from Chiesi, Pfizer, and Zambon. He has received honoraria for lectures at international and national meetings from Almirall, AstraZeneca, Bayer, Chiesi, GSK, Guidotti, Menarini, Novartis, Pfizer, and Zambon. He has served as consultant for Chiesi, Mundipharma, Menarini, and Novartis.

SC has received financial support for research from Novartis and Pfizer. He has served as a consultant for AstraZeneca, Novartis, Chiesi Farmaceutici, Boehringer Ingelheim, GlaxoSmithKline, Mundipharma, and Almirall.

$\mathrm{DR}, \mathrm{SDM}, \mathrm{RR}, \mathrm{VV}$, and MB declare no conflicts of interest in this work.

\section{References}

1. Lozano R, Naghavi M, Foreman K, et al. Global and regional mortality from 235 causes of death for 20 age groups in 1990 and 2010: a systematic analysis for the Global Burden of Disease Study 2010. Lancet. 2012;380(9859):2095-2128. 
2. Celli BR, Cote CG, Marin JM, et al. The body-mass index, airflow obstruction, dyspnea, and exercise capacity index in chronic obstructive pulmonary disease. N Engl J Med. 2004;350(10):1005-1012.

3. Vestbo J, Hurd SS, Agustí AG, et al. Global strategy for the diagnosis, management, and prevention of chronic obstructive pulmonary disease: GOLD executive summary. Am J Respir Crit Care Med. 2013; 187(4):347-365.

4. Barr RG, Bluemke DA, Ahmed FS, et al. Percent emphysema, airflow obstruction, and impaired left ventricular filling. $N \mathrm{Engl} \mathrm{J} \mathrm{Med}$. 2010;362(3):217-227.

5. Watz H, Waschki B, Meyer T, et al. Decreasing cardiac chamber sizes and associated heart dysfunction in COPD: role of hyperinflation. Chest. 2010;138(1):32-38.

6. Grau M, Barr RG, Lima JA, et al. Percent emphysema and right ventricular structure and function: the Multi-Ethnic Study of AtherosclerosisLung and Multi-Ethnic Study of Atherosclerosis-Right Ventricle Studies. Chest. 2013;144(1):136-144.

7. Ather S, Chan W, Bozkurt B, et al. Impact of noncardiac comorbidities on morbidity and mortality in a predominantly male population with heart failure and preserved versus reduced ejection fraction. J Am Coll Cardiol. 2012;59(11):998-1005.

8. Seth HD, Sultan S, Gotfried MH. Role of indacaterol, a once-daily bronchodilator, in chronic obstructive pulmonary disease. $J$ Thorac Dis. 2013;5(6):806-814.

9. Beeh KM, Beier J. Indacaterol, a novel inhaled, once-daily, longacting beta2-agonist for the treatment of obstructive airways diseases. Adv Ther. 2009;26(7):691-699.

10. Buhl R, Dunn LJ, Disdier C, et al; INTENSITY study investigators. Blinded 12-week comparison of once-daily indacaterol and tiotropium in COPD. Eur Respir J. 2011;38(4):797-803.

11. Chapman KR, Rennard SI, Dogra A, Owen R, Lassen C, Kramer B; INDORSE Study Investigators. Long-term safety and efficacy of indacaterol, a long-acting $\beta_{2}$-agonist, in subjects with COPD: a randomized, placebo-controlled study. Chest. 2011;140(1):68-75.

12. Dahl R, Chung KF, Buhl R, et al; INVOLVE (INdacaterol: Value in COPD: Longer Term Validation of Efficacy and Safety) Study Investigators. Efficacy of a new once-daily long-acting inhaled beta2agonist indacaterol versus twice-daily formoterol in COPD. Thorax. 2010;65(6):473-479.

13. Donohue JF, Fogarty C, Lötvall J, et al; INHANCE Study Investigators. Once-daily bronchodilators for chronic obstructive pulmonary disease: indacaterol versus tiotropium. Am J Respir Crit Care Med. 2010;182(2):155-162.

14. Feldman G, Siler T, Prasad N, et al; INLIGHT 1 study group. Efficacy and safety of indacaterol 150 microg once-daily in COPD: a doubleblind, randomised, 12-week study. BMC Pulm Med. 2010;10:11.
15. Korn S, Kerwin E, Atis S, Amos C, Owen R, Lassen C; INSIST study group. Indacaterol once-daily provides superior efficacy to salmeterol twice-daily in COPD: a 12-week study. Respir Med. 2011;105(5):719-726.

16. Kornmann O, Dahl R, Centanni S, et al; INLIGHT-2 (Indacaterol Efficacy Evaluation Using 150- $\mu$ g Doses with COPD Patients) study investigators. Once-daily indacaterol versus twice-daily salmeterol for COPD: a placebo-controlled comparison. Eur Respir J. 2011;37(2):273-279.

17. Laforce C, Aumann J, de Teresa Parreño L, et al; INTEGRAL Study Investigators. Sustained 24-hour efficacy of once daily indacaterol $(300 \mu \mathrm{g})$ in patients with chronic obstructive pulmonary disease: a randomized, crossover study. Pulm Pharmacol Ther. 2011;24(1):162-168.

18. Rudski LG, Lai WW, Afilalo J, et al. Guidelines for the echocardiographic assessment of the right heart in adults: a report from the American Society of Echocardiography endorsed by the European Association of Echocardiography, a registered branch of the European Society of Cardiology, and the Canadian Society of Echocardiography. $J$ Am Soc Echocardiogr. 2010;23(7):685-713; quiz 86-88.

19. Cazzola M, Mantero A, Santus P, et al. Doppler echocardiographic assessment of the effects of inhaled long-acting beta2-agonists on pulmonary artery pressure in COPD patients. Pulm Pharmacol Ther. 2007;20(3):258-264.

20. Santus P, Radovanovic D, Henchi S, et al. Assessment of acute bronchodilator effects from specific airway resistance changes in stable COPD patients. Respir Physiol Neurobiol. 2014;197:36-45.

21. Rossi A, Centanni S, Cerveri I, et al. Acute effects of indacaterol on lung hyperinflation in moderate COPD: a comparison with tiotropium. Respir Med. 2012;106(1):84-90.

22. Boissiere J, Gautier M, Machet MC, Hanton G, Bonnet P, Eder V. Doppler tissue imaging in assessment of pulmonary hypertensioninduced right ventricle dysfunction. Am J Physiol Heart Circ Physiol. 2005;289(6):H2450-H2455.

23. Boussuges A, Pinet C, Molenat F, et al. Left atrial and ventricular filling in chronic obstructive pulmonary disease. An echocardiographic and Doppler study. Am J Respir Crit Care Med. 2000;162(2 Pt 1):670-675.

24. Boussuges A, MolenatF, Burnet H, etal. Operation Everest III(Comex '97): modifications of cardiac function secondary to altitude-induced hypoxia. An echocardiographic and Doppler study. Am J Resp Crit Care Med. 2000;161(1):264-270.

25. Cazzola M, Page CP, Rogliani P, Matera MG. $\beta 2$-agonist therapy in lung disease. Am J Respir Crit Care Med. 2013;187(7):690-696.

26. Decramer ML, Hanania NA, Lotvall JO, Yawn BP. The safety of long-acting $\beta 2$-agonists in the treatment of stable chronic obstructive pulmonary disease. Int J Chron Obstruct Pulmon Dis. 2013;8:53-64.
International Journal of COPD

\section{Publish your work in this journal}

The International Journal of COPD is an international, peer-reviewed journal of therapeutics and pharmacology focusing on concise rapid reporting of clinical studies and reviews in COPD. Special focus is given to the pathophysiological processes underlying the disease, intervention programs, patient focused education, and self management protocols.

\section{Dovepress}

This journal is indexed on PubMed Central, MedLine and CAS. The manuscript management system is completely online and includes a very quick and fair peer-review system, which is all easy to use. Visit http://www.dovepress.com/testimonials.php to read real quotes from published authors. 